\title{
LCA OF HEAVY METALS LEACHING FROM LANDFILLED SEWAGE SLUDGE ASH
}

\author{
Domagoj NAKIĆ ${ }^{*}$, Dražen VOUK ${ }^{2}$, Mario ŠILJEG $^{1}$, Anđelina BUBALO ${ }^{2}$ \\ ${ }^{1}$ Civil Engineering Department, University North, Jurja Križanića 31b, 42000 Varaždin, Croatia \\ ${ }^{2}$ Faculty of Civil Engineering, University of Zagreb, Kačićeva 26, 10000 Zagreb, Croatia
}

Received 14 February 2021; accepted 14 May 2021

\author{
Highlights \\ Sewage sludge ash has a resource potential, but it is still mostly landfilled. \\ $>$ LCA model is used to assess the environmental impacts of landfilled SSA. \\ The impact of leaching of hazardous and potentially toxic heavy metals is analyzed. \\ $>$ Leaching of Se and $\mathrm{Hg}$, and to a lesser extent $\mathrm{Cd}$ and $\mathrm{Ni}$, shows the biggest impact. \\ $>$ In the SSAs obtained from Croatian sludge Mo leaching also has a dominant impact.
}

\begin{abstract}
Quantities of sewage sludge that are thermally treated (mostly incinerated) are increasing, resulting in growing quantities of sewage sludge ash (SSA) which also requires further management. Despite its potential as a resource, it is still largely landfilled. Considering the presence of potentially toxic and hazardous heavy metals in SSA, this paper analyzes how the change in the leaching concentrations of the selected heavy metals from landfilled SSA impacts the environment (air, water, and soil) by the means of LCA. When considering human toxicity potential as impact category, dominant impacts were due to emissions into the air, primarily caused by leaching of selenium and somewhat less cadmium, mercury and nickel. Mercury had a dominant impact when considering the terrestrial ecotoxicity potential impact. In the SSAs obtained from Croatian sludge, molybdenum leaching, along with selenium and mercury, showed a dominant impact. Therefore, due to the high variability of trace elements, detailed analysis of different SSAs is needed.
\end{abstract}

Keywords: heavy metals, landfills, LCA, leaching, sewage sludge ash.

\section{Introduction}

At the global level, a significant amount of waste in the form of sewage sludge from wastewater treatment plants (WWTP) is generated. Sewage sludge treatment aims to reduce its total mass and volume to facilitate its further management, for which thermal treatment technologies are successfully applied. Sewage sludge ash (SSA) is the main by-product formed in the combustion processes associated with thermal processing. Sludge management should meet all sustainability requirements: solutions must be acceptable to the public and cost-effective, but at the same time they must respect the requirements for efficient recycling of all by-products while ensuring safety for human health and the environment (Lundin et al., 2004).

Disposal of sewage sludge within the global practice is carried out in different ways. There is no unique strategy or guidance, and each country addresses the sludge management problem in its own way. Even at EU level, there are significant differences in sewage sludge management between countries (Figure 1). Analyzing the data for 2013-2017 period, some changes in the disposal routes of sewage sludge can be observed for individual countries, with an increase in the share of thermal treatment (incineration and co-incineration) and the resulting decrease in use on agricultural and non-agricultural land. Although incineration technologies represent significant investment costs, sludge incineration is the dominant method in the Netherlands, Switzerland, Belgium, Germany, Austria, and Slovenia (Eurostat, 2019; Europäischen Wirtschaftsdienst [EUWID], 2018). According to Lynn et al. (2015), about $22 \%$ of generated sludge at the EU level was incinerated with a trend of a constant increase in these quantities. By incinerating 1 tonne of dehydrated sludge, which, among

*Corresponding author. E-mail: dnakic@unin.hr 


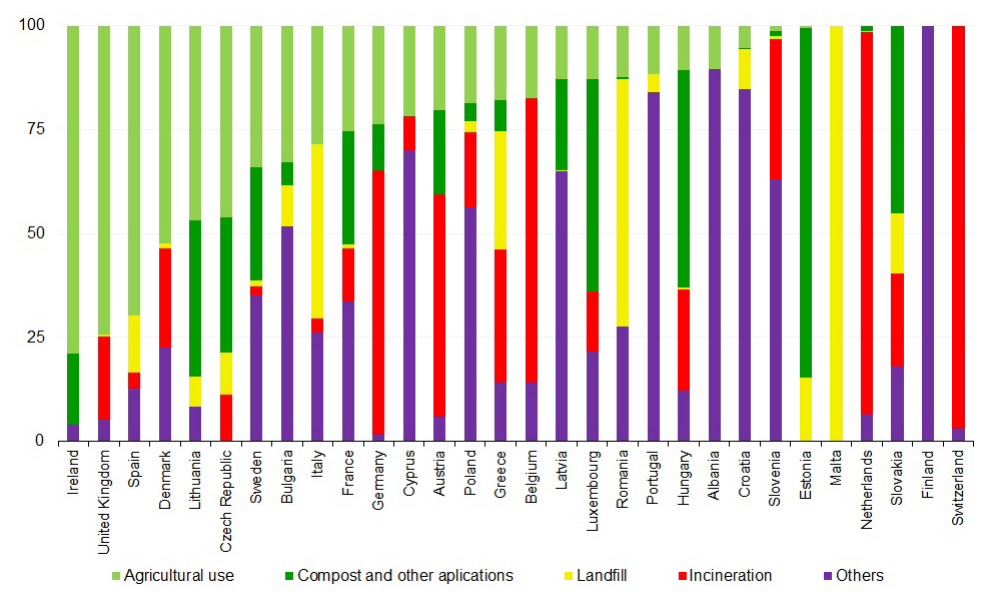

Figure 1. Sewage sludge management in European countries in 2017 (Updated data by Eurostat, 2019)

other compounds, contains numerous pathogens and heavy metals, about $100 \mathrm{~kg}$ of sterile SSA is generated (Nakić et al., 2017).

This means, even the incineration of the sludge does not completely solve the problem of its disposal, as new waste, SSA, is generated, and it also needs to be further managed (disposed or used/recycled). Despite its potential as a resource, SSA is still largely disposed in landfills for non-hazardous waste. In Germany, for example, most of the SSA generated is used to fill trenches and drill holes (37\%), while about $29 \%$ is landfilled. A similar share (almost $29 \%$ ) is used for land rehabilitation and construction services for purposes such as road construction, while the smallest share (about $5 \%$ ) is used directly in agriculture (Krüger \& Adam, 2015). In Austria, about 50\% of the generated sewage sludge is incinerated with the subsequent disposal of SSA in the specially equipped landfills (Eurostat, 2019).

\section{Literature review in the field of research}

\subsection{Composition of sewage sludge and SSA regarding the environmental impact of potentially toxic and hazardous elements and compounds}

The main barriers to the use of sewage sludge are contaminants such as heavy metals, organic compounds, and pathogenic microorganisms that can be highly concentrated in the sludge. Heavy metals in sewage sludge can be harmful to humans, especially if they enter the food chain (Fytili \& Zabaniotou, 2008). Sewage sludge can also be harmful to the soil on which it is used (agricultural and non-agricultural), contributing to its pollution, but also to the pollution of surface and groundwater bodies in which by natural phenomena (rain, snow, wind) can leach.

Regarding potential sludge treatment solutions, the content of heavy metals is reduced only by thermal treatment at higher temperatures (incineration, pyrolysis, gasification). Heavy metals such as mercury, cadmium, antimony, arsenic and lead are partially or fully combusted by sludge incineration.
X-ray fluorescence spectrometer analysis of SSA consistently reveals that the main contained elements (with oxygen) are silicon, iron, aluminum, calcium, and phosphorus. However, significant contents of heavy metals have also been observed, which are concentrated in the SSA when sludge is incinerated (Dhir et al., 2017; Donatello \& Cheeseman, 2013; Chang et al., 2020; Cyr et al., 2007; Lynn et al., 2018). According to some studies, trace heavy metals are found in SSA due to their condensation on the ash particles after the temperature decrease inside the incineration plant. If SSA is landfilled or used in construction after incineration, the major problem with leaching of heavy metals comes from antimony, molybdenum, and selenium (Chen et al., 2013; Donatello et al., 2010).

Regarding the content of hazardous and potentially toxic substances found in SSA, it is necessary to assess their impact on human health and the environment. Heavy metals are one of the basic controlled parameters when conducting such assessments, or more precisely their leaching concentrations are considered since it is the part that is biologically available. This is due to the fact that all precaution and protection measures need to be applied when SSA management is planned to eliminate or at least minimize environmental impacts. This research aims to show how a change in the concentration of heavy metals leaching from landfilled SSA impacts the environment by analyzing their emissions into the air, water and soil.

\subsection{SSA landfilling}

Given that the landfilling of neither sewage sludge nor SSA is not a solution that is based on the basic tenets of sustainability, numerous research have been conducted to evaluate the possibilities of their use in other applications, primarily in the construction materials industry (Donatello \& Cheeseman, 2013; Nakić et al., 2017; Vouk et al., 2016). Landfilling of waste, including SSA, is a financially and environmentally sensitive process, which is particularly significant in regions with stricter legislation. Proper waste management is also one of the basic principles of sustainability and circular economy. 


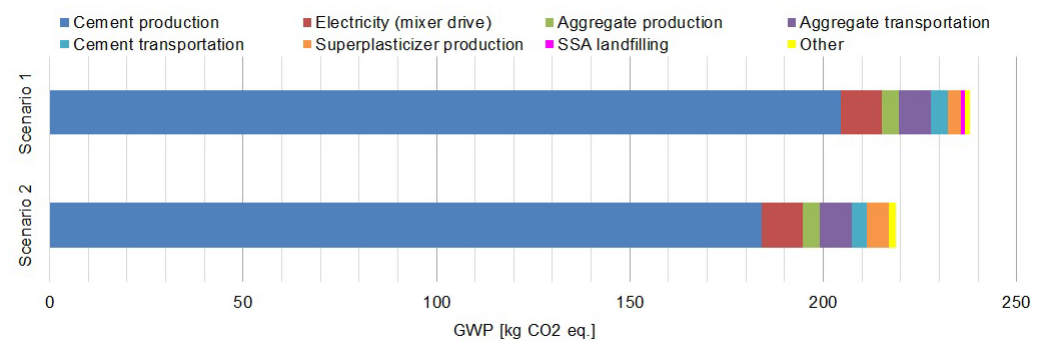

Figure 2. Results of the LCA model for two compared scenarios expressed as GWP (Scenario 1- production of $1 \mathrm{~m}^{3}$ of ordinary concrete and landfilling those quantities of SSA used as a substitute for cement in scenario 2; Scenario $2-$ production of $1 \mathrm{~m}^{3}$ of concrete by substituting $10 \%$ of cement with SSA) (Nakić, 2018)

The costs of SSA landfilling vary significantly between countries and even regions, with the crucial factor being the categorization of SSA in relation to its suitability for a particular type of landfill. Fischer et al. (2012) state that the landfill tax could vary from a relatively low price as $1-2 € / t$ to up to $200 € / t$. For example, landfilling of 1 tonne of non-hazardous waste amounts to about $50 €$ in Zagreb, Croatia. At the same time, the landfill tax for inert waste is about 20 times lower (about $2.5 €$ per tonne). Similar or even more pronounced differences are present in most other countries, for example in the UK the landfill tax for inert waste is the same, $2.5 €$ per tonne, while for the nonhazardous waste it is over 30 times higher ( $80 €$ per tonne) (Nakić et al., 2017). This directly highlights the importance of understanding the composition of SSA prior to considering its landfilling. According to EU regulations (Hazardous Waste Directive and Waste Acceptance Criteria - WAC) SSA is classified by a waste number $190113^{*}$ in the European Waste Catalogue. Hereby the SSA is designated as non-hazardous waste, of course, provided that the prescribed limit values of leaching of individual elements (primarily heavy metals) are met (Nakić et al., 2017).

Donatello et al. (2010) marked selenium, molybdenum, and antimony as the elements of most concern regarding the WAC for non-hazardous waste landfills. Nakić et al. (2017) found molybdenum and chromium as the main heavy metals of concern in the context of landfill WAC.

Recent research is mostly focused on diverting SSA from landfill and using SSA whenever it is possible, for example in construction materials like cement mortars, concrete, bricks, and tiles (Areias et al., 2020; Chang et al., 2020; Chen et al., 2018; He \& Wang; 2019; Nakić et al., 2020; Oliva et al., 2019; Ottosen et al., 2020; Świerczek et al., 2018; Vouk et al., 2018; Zhou et al., 2020a, 2020b). Also, some studies have proven that the heavy metals from the SSA are encapsulated within the construction material produced (concrete, cement mortar, bricks), which results in a reduction of their leaching and makes the resulting product environmentally friendly (Donatello \& Cheeseman, 2013; Cyr et al., 2007; Nakić et al., 2017; Vouk et al., 2016).

\subsection{Life Cycle Assessment as a method of determining environmental impacts resulting from SSA landfilling}

The Life Cycle Assessment (LCA) is, among other similar methods, a very practical tool for assessing the potential environmental impacts that occur as a result of waste (SSA) landfilling. The main environmental impacts of landfilling are manifested as leachate and air emissions. Given that it is very demanding and very unlikely to collect empirical data on the emissions of individual waste (e.g., sludge or ash), usually the data on general emissions from mixed municipal waste landfills are taken for analysis or in a more precise case these can be limited to specific categories of waste and landfills (Suh \& Rousseaux, 2002). In such study based on LCA conducted in Germany, Wittmaier et al. (2009) reported that disposal of waste in landfills results in two times higher greenhouse gas emissions compared to thermal treatment of the same amount of waste under controlled conditions.

Based on the literature review and previous research (Gursel et al., 2014; Nakić, 2018), it is valid to simplify LCA models by clearly setting system boundaries on the "gate-to-grave" principles. For this approach, the boundaries of the analyzed system start with obtained SSA that requires further management and end with considering environmental impacts which occur within the End-ofLife phase of the residue disposed of at the non-hazardous waste landfill. So, within this research, environmental impacts of obtaining SSA are not analyzed, i.e., SSA is considered as an undesirable residue, or by-product. Therefore, the aim of this paper is not to compare different sludge disposal methods (which are concisely analyzed in the means of LCA by Lombardi et al. (2017)), as the starting point in this research is the SSA generated within the sludge mono-incinerator.

From an LCA perspective, residue utilization provides benefits as a result of avoiding the production and depletion of primary materials, but it can generate environmental burdens, due to the leaching of potentially dangerous and toxic elements and compounds (Allegrini et al., 2015). The important fact is that heavy metals are usually well incorporated in cement matrix if SSA is used in concrete/ 
mortar mixtures and as such remain immobilized (Nakić et al., 2017; Shih et al., 2005; Lin \& Weng, 2001).

Previous research (Nakić, 2018) has shown that SSA landfilling does not cause significant environmental impacts, given the potential for global warming. According to Nakić (2018) production of $1 \mathrm{~m}^{3}$ of normal commonly used concrete and landfilling of SSA in the amount that is used as a cement replacement (10\%) to obtain concrete of the same mechanical, durability and ecological properties results in a total GWP of $238 \mathrm{~kg} \mathrm{CO}_{2}$ eq. (Figure 2 - Scenario 1). In contrary, production of $1 \mathrm{~m}^{3}$ of experimental "green" concrete with $10 \%$ of cement replaced by SSA and eliminating the need to landfill these quantities of SSA on the non-hazardous waste landfill, the total GWP is about 9\% lower and is $219 \mathrm{~kg} \mathrm{CO}_{2}$ eq. (Figure 2 - Scenario 2). Similar ratios (5-11\% lower potential impacts when SSA is used in concrete, with average value near 9\%) were obtained when other impact categories were selected (abiotic depletion potential, ozone layer depletion potential, photochemical ozone creation potential, acidification potential, eutrophication potential). Although this research concluded that landfilling of SSA does not impose a significant environmental impact for GWP impact category, it also points out the need of conducting more detailed analysis on different heavy metals ratios in SSA since their variations could significantly impact results within some other impact categories that are more sensitive to their influence like human toxicity potential (HTP) and terrestrial ecotoxicity potential (TETP). In doing so, heavy metals, but also other elements and compounds such as radionuclides, are primarily considered.

\section{Experimental research}

\subsection{Methodology}

LCA was conducted using the software GaBi Professional which includes the life cycle inventory (LCI) extension database End of life.

Considering the content of dangerous and potentially toxic elements and compounds in ash, but also the need to reduce the effects on all environmental components by the compulsory implementation of certain protection measures, their impact on human health is observed by HTP and impact on the environment in general by TETP. As part of this study, only heavy metals content and the concentration of their leaching from ash were examined (data available from the literature reviewed is also limited to heavy metals in ash), so the following analysis will primarily consider the environmental impact of 10 selected heavy metals caused by their leaching from SSA landfilled on non-hazardous waste landfill. Nevertheless, the same methodological principle is applicable in the case of having a much larger database of input data.

\subsection{Data and materials used}

By combining the test results of SSA obtained by laboratory incineration of sludge originated from several WWTPs from the territory of Croatia (Karlovac, Koprivnica, Varazdin and Zagreb) and the results of the literature review, the ranges (min - max) in the leaching concentrations of 10 considered heavy metals (arsenic, cadmium, chromium, copper, lead, mercury, molybdenum, nickel, selenium, and zinc) at the global level were determined (Table 1 and Figure 3). As mentioned before, in the case of the availability of broader parameter analysis, the same principle applies. Leaching concentrations were used as relevant since the leached (released) heavy metals pose a danger to human health and the environment.

The methodology for collecting, drying and incineration of sewage sludge in the laboratory, as well as the method of conducting leaching tests on SSA is described in detail in the paper by Nakić et al. (2017).

\subsection{Model settings}

For ease of entering leaching concentrations of heavy metals, the functional unit of the LCA model is defined as

Table 1. Range of heavy metal leaching concentrations from SSA $[\mathrm{mg} / \mathrm{l}]$ based on literature review and additional testing performed in this paper and within the RESCUE project with emphasized mean values for Croatia and at the world level (Chen et al., 2006; Chen \& Lin; 2009; Chen et al., 2013; Chen \& Poon; 2017; Cyr et al., 2012; Donatello et al., 2010; Fontes et al., 2004; Li et al., 2016; Shi \& Kan; 2009)

\begin{tabular}{|c|c|c|c|c|}
\hline $\begin{array}{c}\text { Para- } \\
\text { meter }\end{array}$ & Min & $\begin{array}{c}\text { Mean } \\
\text { (Croatia) }\end{array}$ & $\begin{array}{c}\text { Mean } \\
\text { (worldwide) }\end{array}$ & Max \\
\hline $\mathrm{As}$ & 0 & 0.014423 & 0.749679 & 7.700 \\
\hline $\mathrm{Cd}$ & 0 & 0.000035 & 0.637306 & 10.500 \\
\hline $\mathrm{Cr}$ & 0.0200 & 0.889592 & 8.471924 & 152.000 \\
\hline $\mathrm{Cu}$ & 0 & 0 & 8.033900 & 82.400 \\
\hline $\mathrm{Ni}$ & 0 & 0 & 1.449706 & 19.700 \\
\hline $\mathrm{Pb}$ & 0 & 0.015483 & 0.611745 & 4.000 \\
\hline $\mathrm{Zn}$ & 0 & 0.045667 & 7.779211 & 81.400 \\
\hline $\mathrm{Hg}$ & 0 & 0.000253 & 0.025037 & 0.212 \\
\hline $\mathrm{Mo}$ & 1.1428 & 4.880133 & 8.662914 & 19.500 \\
\hline $\mathrm{Se}$ & 0.0192 & 0.054493 & 1.384831 & 12.200 \\
\hline
\end{tabular}

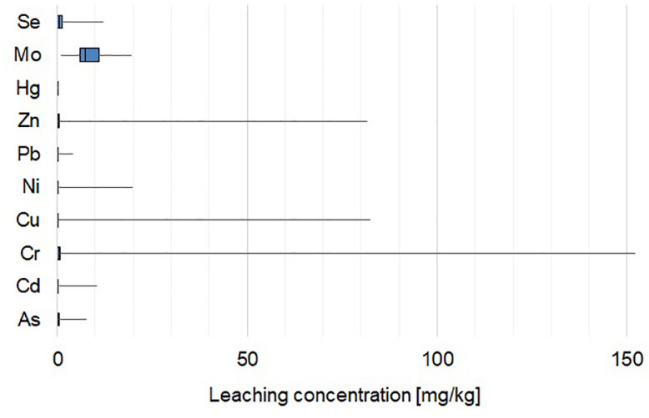

Figure 3. Range of heavy metal leaching concentrations combined results of literature review and additional testing performed with SSAa within this research (Chen et al., 2006, 2013; Chen \& Lin; 2009; Chen \& Poon; 2017; Cyr et al., 2012; Donatello et al., 2010; Fontes et al., 2004; Li et al., 2016; Shi \& Kan; 2009) 


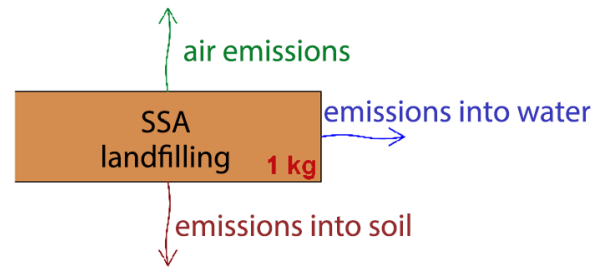

Figure 4. A simplified schematic representation of the LCA model used to assess the impact of heavy metals when SSA is deposited in landfills for non-hazardous waste

$1 \mathrm{~kg}$ of SSA landfilled in a non-hazardous waste landfill (Figure 4). The impact of leaching of certain heavy metals on emissions to the three basic environmental components (air, water and soil) is further considered. To create the described LCA model GaBi Professional computer software was used, while emissions and other environmental impacts are directly linked from built-in databases. Human toxicity potential (HTP) and terrestrial ecotoxicity potential (TETP) were selected as indicators to assess environmental impacts.

An overall analysis of their environmental impact will be provided through separate analyzes of emissions into the air, water, and soil. When analyzing the potential environmental impacts expressed through the human and environmental toxicity categories, results from worldwide practice are most reported in [kg DCBeq.]. Therefore, the same unit of measure will also be applied within the proposed methodology.

The analysis aims to examine how changes in the leaching concentration of a single heavy metal, within realistically expected ranges defined in Table 1, affects the potential environmental impacts of ash landfilling. In other words, a sensitivity analysis was performed to determine the dependence of the toxicity potential on humans and the environment regarding the change in the leaching concentration of a single heavy metal. The analysis is expected to specify more precisely which parameters need to be addressed when analyzing the ash composition, which can be neglected, and which would ultimately contribute to the optimization of the quality control of the ash deposited at landfills.

\section{Results and discussion}

\subsection{Model results}

Figure 5 shows the results of the LCA model expressed as HTP, and Figure 6 shows the results of the same LCA model expressed as TETP. From the comparison of the results obtained it is concluded that when conducting such analyzes, it is necessary to analyze the results expressed through both impact categories, since certain metals that are extremely toxic to humans are not equally toxic to the environment and vice versa. It is also evident that, within both sets of results, the impacts due to emissions of heavy metals into the air are dominant over the impacts caused by emissions into the water and soil
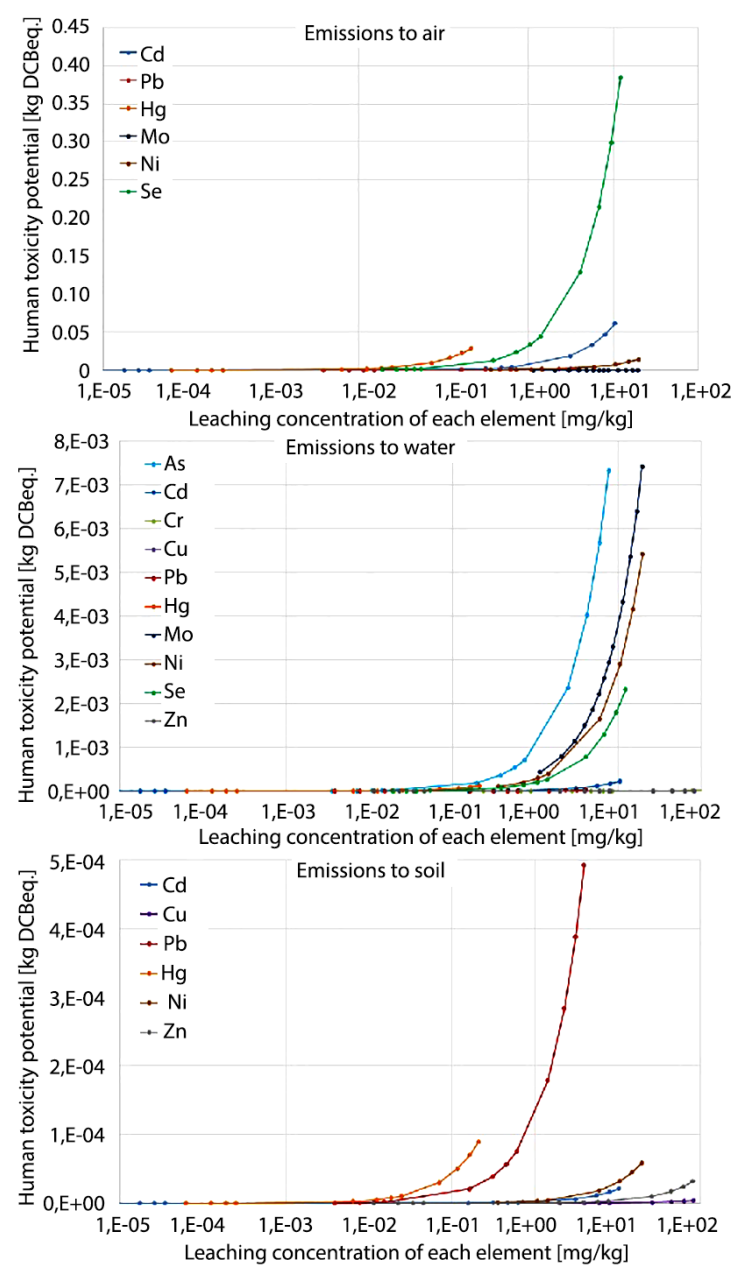

Figure 5. LCA model results - HTP dependence on leaching concentrations of selected heavy metals

(environmental impacts due to air emissions are up to several orders of magnitude higher in absolute amounts than impacts caused by emissions of heavy metals into the water and soil). This can be attributed to the fact that the effects of ash deposited on landfills of non-hazardous waste are analyzed, i.e., emissions into water and soil are significantly reduced by the protective measures that are usually implemented at landfills of this type (filter and impermeable layers in the lower part of the landfill, leachate collection and treatment, etc.). A more detailed analysis of the results shows that, when landfilling SSA at non-hazardous waste landfills, the predominant effect on HTP is the result of emissions into the air, primarily caused by selenium leaching, and to lesser extent cadmium, mercury and nickel leaching, while the toxic effects on humans through water and soil were up to several times smaller. The impacts through emissions into the water are mostly the result of arsenic, cadmium, nickel, and selenium leaching, while the emissions into the soil are mostly caused by lead and mercury. When analyzing the impact on TETP, the results of the analysis have shown that mercury is the dominant factor, primarily through air emissions. The effects of all other analyzed metals are practically negligible, except for zinc when 


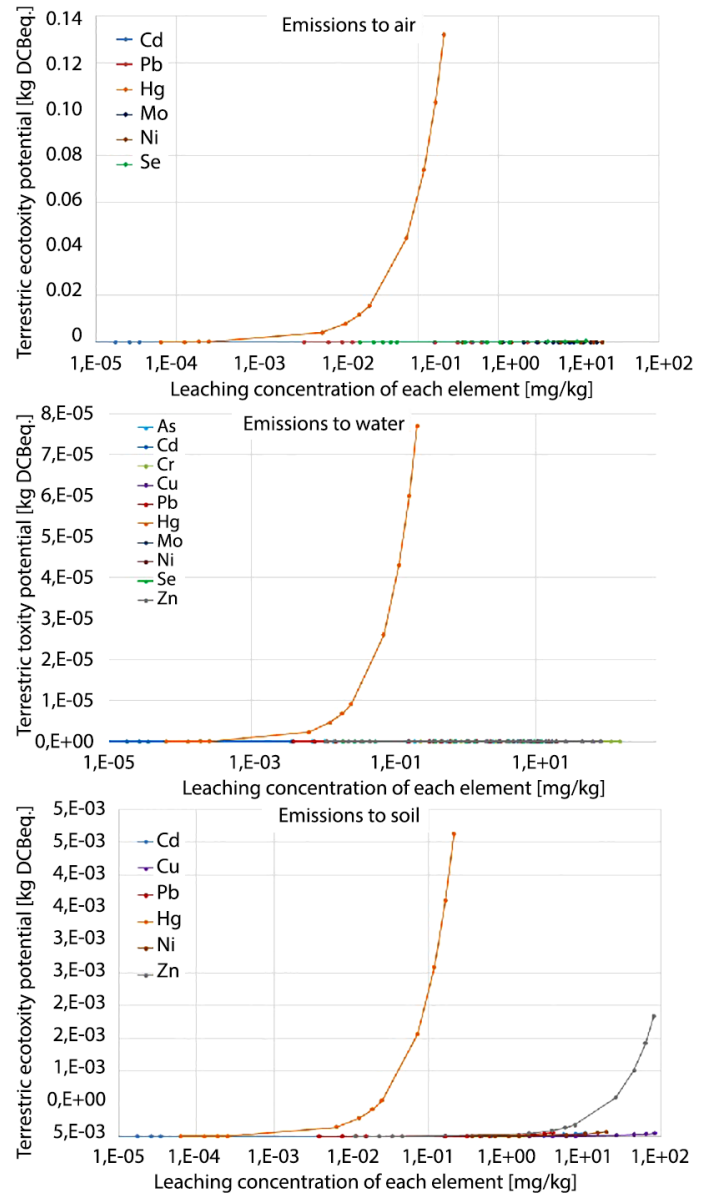

Figure 6. LCA model results - TETP dependence on leaching concentrations of selected heavy metals

emissions to soil were considered. It should be noted here that mercury, in respect to all the metals analyzed, is present in the lowest concentrations and that any change in the concentration of mercury leaching, even within such a small range (Table 1 and Figure 3), causes significant changes in the increase of environmental impact expressed as TETP. Therefore, mercury is one of the key parameters that needs to be analyzed and controlled when depositing SSA in landfills.
Selenium is in the category of parameters that need to be analyzed and controlled in any case, since in absolute terms its effects on HTP, primarily through emissions into the air, far outweighs the impacts of to the emissions of all other analyzed metals together. On the other hand, heavy metals present at the highest concentrations (like copper and zinc) do not generate significant environmental impacts expressed as HTP and TETP. Even the extreme concentration of chromium leaching observed in a single ash sample within the literature reviewed does not generate significant toxicity to humans or the environment.

\subsection{Model results relevant to the territory of Croatia}

A more detailed analysis of the results within the applied LCA model for leaching concentrations of heavy metals relevant to the territory of Croatia (Figure 7) shows that, in respect to human toxicity, molybdenum (via water emissions) and selenium (via air emissions) are the most problematic elements, which is in line with the conclusions of Donatello et al. (2010). Given the TETP mercury in this case also proved to be the dominant factor. This shows a disparity between the impacts on HTP via air and water emissions when SSA from Croatia is compared to SSA with maximum concentrations of heavy metals leaching taken from the reviewed literature. This is because SSA from the territory of Croatia shows relatively high molybdenum leaching concentrations in relation to the leaching concentrations of other analyzed heavy metals when it is compared to SSA generated globally (Table 1). Also, molybdenum alone significantly influences HTP by the emissions into the water (Figure 5 and Figure 7). Namely, the concentration of molybdenum leaching from SSA from the territory of Croatia is as high as $25 \%$ of the maximum leaching concentration of this metal within the reviewed literature, and the leaching concentrations of all other analyzed ash metals from the territory of Croatia are below $1 \%$ of their maximum leaching concentrations recorded worldwide.
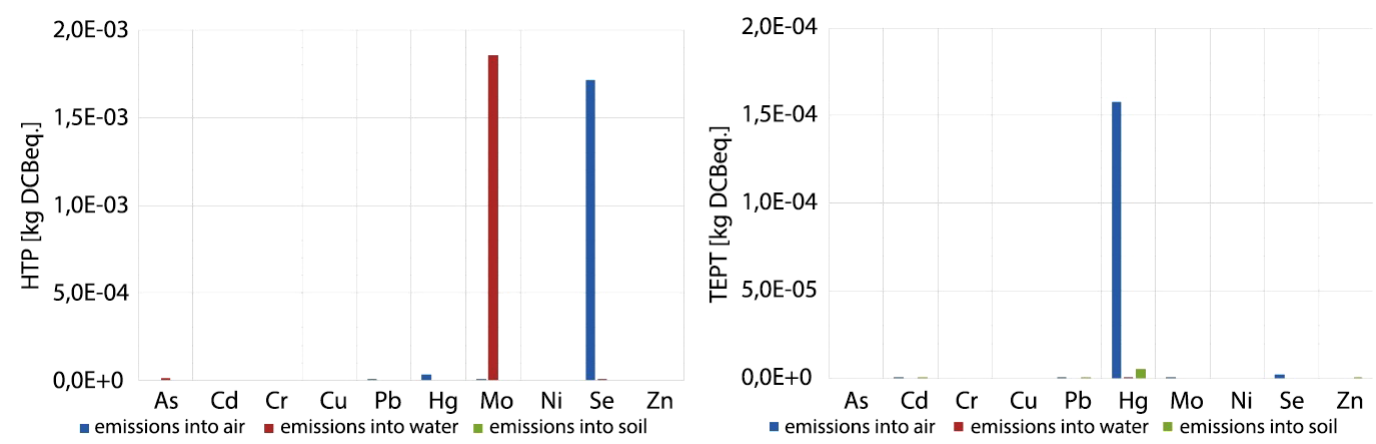

Figure 7. LCA model results - HTP (left) and TETP (right) based on the mean leaching values of selected heavymetals from ash from Croatia 


\subsection{Significance of the obtained results and discussion}

To get a better insight into the significance of the values obtained and the significance of the results reported in [kg DCBeq.], the results can be linked to the maximum permissible concentrations of DCB in drinking water of $75 \mu \mathrm{g} / \mathrm{l}$ prescribed by the EPA or the maximum permissible concentrations of DCB indoors of $75 \mathrm{ppm}$ (about $450 \mathrm{mg} / \mathrm{m}^{3}$ ), since there are no criteria for these parameters in national regulations. According to the results of the LCA model, the potential emissions into water and air due to leaching of all analyzed heavy metals during the deposition of $1 \mathrm{~kg}$ of SSA from the territory of Croatia, expressed as HTP, are respectively 0.001881124 [kg DCBeq.] and 0.001763496 [kg DCBeq.]. This means that $1 \mathrm{~kg}$ of landfilled ash has the potential to contaminate over $25 \mathrm{~m}^{3}$ of drinking water, or nearly $4 \mathrm{~m}^{3}$ of air, while the total quantity of ash that is expected to be generated at WWTP Zagreb $(16,500 \mathrm{t}$ of ash per year) could potentially pollute over 400 million $\mathrm{m}^{3}$ of drinking water, or over 60 million $\mathrm{m}^{3}$ of air.

In the case of ash with a significantly less favorable composition, that is, ash with higher concentrations of leaching of heavy metals, it is possible to expect many times higher pollution potential. The LCA model showed that potential emissions into air and water due to leaching of the analyzed heavy metals resulting from $1 \mathrm{~kg}$ of landfilled ash with maximum reported leaching concentrations of individual heavy metals (Table 1), and expressed as HTP, are respectively 0.022882198 [kg DCBeq.] and 0.48843125 [kg DCBeq.]. This means that $1 \mathrm{~kg}$ of such SSA has the potential to pollute over $300 \mathrm{~m}^{3}$ of drinking water, i.e., over $1,000 \mathrm{~m}^{3}$ of air. The results obtained indicate that the disposal of ash at unregulated landfills should not be allowed without a protective and filter layer and a leachate collection with effective treatment system.

\subsection{Comparison with the results of previous research where SSA was used in construction materials}

Having previously analyzed (Nakić et al., 2017; Nakić, 2018) leaching from monolithic mortar specimens and from mortar and concrete fragments in which SSA was used as a partial cement replacement, it has been established that heavy metals leaching is at par as that of the reference composites. The same trend was also reported by Cyr et al. (2007), Chen et al. (2013), Donatello et al. (2010) and Coutand et al. (2006), who conclude that concrete with a $10 \%$ SSA content, when crushed at its Endof-Life, meets the requirements for disposal in inert waste landfills or it can be recycled and used as aggregates in new construction products. Leaching of heavy metals from mortars with incorporated SSA at the same level as leaching from reference samples is also shown in the work by Cyr et al. (2012). A similar conclusion was reached by Lynn et al. (2018) analyzing the leaching of heavy metals from ceramic materials with incorporated SSA characterizing it as very low, even below the most stringent drinking water parameters. Mohajerani et al. (2018) pointed that the results of the LCA show that the incorporation of sewage sludge/SSA in bricks is environmentally favorable and promising alternative approach. Furthermore, it can be concluded that the effects of SSA on the environment and human health are significantly reduced by its use in the industry of construction materials as opposed to the disposal of SSA in landfills. Therefore, the sewage sludge and SSA management, which is based on connecting the wastewater treatment industry (where significant amounts of waste that require expensive and environmentally sensitive disposal are generated) and the construction materials industry, as one of the most significant consumers of raw materials, aims to develop a circular economy. It can be assumed that such an application could provide additional economic benefits, especially considering the announced EU penalties for inappropriate waste management. The readiness of the market to accept sewage sludge and SSA in construction products is unquestionable, but special emphasis is placed on the need to conduct further research and to provide regulatory support by introducing new legislation.

\section{Conclusions}

The performed analyzes examined how the change in heavy metals leaching concentrations (within the realistically expected ranges) influences potential environmental impacts caused by the disposal of SSA in non-hazardous waste landfills. When considering HTP as impact category, the dominant impacts arise as a result of emissions into the air, primarily caused by leaching of selenium and to lesser extent cadmium, mercury and nickel. Mercury has shown to be the dominant parameter when considering the TETP impact category. Although selenium and mercury, as well as cadmium and nickel to a lesser extent, are identified as key parameters for analysis, the need for detailed analyzes of different ashes is particularly emphasized due to the high variability in the contents of the trace elements. For SSAs obtained by incineration of Croatian sludge, dominant parameters are somewhat different: with selenium and mercury due to air emissions, molybdenum leaching due to water emissions proved to have a dominant impact.

The results of the analyzes carried out may, among other things, serve to supplement the legislation with respect to defining the necessary parameters for control during the disposal of SSA in landfills.

\section{Acknowledgements}

This work has been fully supported by Croatian Science Foundation under the project "IP-2019-04-1169 - Use of treated oily wastewater and sewage sludge in brick industry - production of innovative brick products in the scope of circular economy". 


\section{References}

Allegrini, E., Butera, S., Kosson, D. S., Van Zomeren, A., Van der Slot, H. A., \& Astrup, T. F. (2015). Life cycle assessment and residue leaching: The importance of parameter, scenario and leaching data selection. Waste Management, 38, 474-485. https://doi.org/10.1016/j.wasman.2014.12.018

Areias, I. O. R., Vieira, C. M. F., Colorado, H. A., Delaqua, G. C. G., Monteiro, S. N., \& Azevedo, A. R. G. (2020). Could city sewage sludge be directly used into clay bricks for building construction? A comprehensive case study from Brazil. Journal of Building Engineering, 31, 101374. https://doi.org/10.1016/j.jobe.2020.101374

Chang, Z., Long G., Zhou, J. L., \& Ma, C. (2020). Valorization of sewage sludge in the fabrication of construction and building materials: A review. Resources. Conservation and Recycling, 154, 104606. https://doi.org/10.1016/j.resconrec.2019.104606

Chen, C. H., Chiou, I. J, \& Wang, K. S. (2006). Sintering effect on cement bonded sewage sludge ash. Cement Concrete and Composites, 28(1), 26-32.

https://doi.org/10.1016/j.cemconcomp.2005.09.003

Chen, M., \& Lin, D. F. (2009). Stabilization treatment of soft subgrade soil by sewage sludge ash and cement. Journal of Hazardous Materials, 162(1), 321-327.

https://doi.org/10.1016/j.jhazmat.2008.05.060

Chen, M., Blanc, D., Gautier, M., Mehu, J., \& Gourdon, R. (2013). Environmental and technical assessments of potential utilization of sewage sludge ashes (SSAs) as secondary raw materials in construction. Waste Management, 33(5), 1268-1275. https://doi.org/10.1016/j.wasman.2013.01.004

Chen, Z., \& Poon, C. C. (2017). Comparing the use of sewage sludge ash and glass powder in cement mortars. Environmental Technology, 38(11), 1390-1398.

https://doi.org/10.1080/ 09593330.2016.1230652

Chen, Z., Li J. S., \& Poon, C. S. (2018). Combined use of sewage sludge ash and recycled glass cullet for the production of concrete blocks. Journal of Cleaner Production, 171, 1447-1459. https://doi.org/10.1016/j.jclepro.2017.10.140

Coutand, M., Cyr, M., \& Clastres, P. (2006). Use of sewage sludge ash as mineral admixture in mortars. Construction Materials, 159(4), 153-162. https://doi.org/10.1680/coma.2006.159.4.153

Cyr, M., Coutand, M., \& Clastres, P. (2007). Technological and environmental behavior of sewage sludge ash (SSA) in cement-based materials. Cement and Concrete Research, 37(8), 1278-1289. https://doi.org/10.1016/j.cemconres.2007.04.003

Cyr, M., Idir, R., \& Escadeillas, G. (2012). Use of metakaolin to stabilize sewage sludge ash and municipal solid waste incineration fly ash in cement-based materials. Journal of Hazardous Materials, 243, 193-203.

https://doi.org/10.1016/j.jhazmat.2012.10.019

Dhir, R. K., Ghataora, G. S., \& Lynn, C. J. (2017). Sewage sludge ash characteristics. In Sustainable construction materials: Sewage sludge ash (1st ed., pp. 69-110). Woodhead Publishing. https://www.sciencedirect.com/science/article/pii/ B9780081009871000044?via\%3Dihub

Donatello, S., \& Cheeseman, C. R. (2013). Recycling and recovery routes for incinerated sewage sludge ash (ISSA): A review. Waste Management, 33(11), 2328-2340. https://doi.org/10.1016/j.wasman.2013.05.024

Donatello, S., Tyrer, M., \& Cheeseman, C. R. (2010). EU landfill waste acceptance criteria and EU Hazardous Waste Directive compliance testing of incinerated sewage sludge ash. Waste Management, 30(1), 63-71.

https://doi.org/10.1016/j.wasman.2009.09.028
Europäischen Wirtschaftsdienst. (2018). Die neue Klärschlammverordnung: Paradigmenwechsel für die Abwasserentsorgung (Report Klärschlamm). Euwid Wasser und Abwasser. EUWID. http://bi-bachlertal.de/wp-content/uploads/2020/01/ Euwid-K1\%C3\%A4rschlammreport-2018.pdf

Eurostat. (2019). Sewage sludge production and disposal. http:// appsso.eurostat.ec.europa.eu/nui/show.do?dataset=env_ww_ spd\&lang=en

Fischer, C., Lehner, M., \& Mckinnon, D. L. (2012). Overview of the use of landfill taxes in Europe (Working Paper). European Topic Centre on Sustainable Consumption and Production.

Fontes, C. M. A., Barbosa, M. C., Toledo Filho, R. D., \& Goncalves, J. P. (2004). Potentiality of sewage sludge ash as mineral additive in cement mortar and high performance concrete. In Proceedings of the Intern. RILEM Conference on the Use of Recycled Materials in Buildings and Structures (pp. 797-806). Barcelona, Spain. https://www.researchgate. net/profile/Romildo-Toledo-Filho/publication/228479791_ Potentiality_of_sewage_sludge_ash_as_mineral_additive_in_cement_mortar_and_high_performance_concrete/ links/02e7e51cb590023011000000/Potentiality-of-sewagesludge-ash-as-mineral-additive-in-cement-mortar-and-highperformance-concrete.pdf

Fytili, D., \& Zabaniotou, A. (2008). Utilization of sewage sludge in EU application of old and new methods - A review. Renewable and Sustainable Energy Reviews, 12(1), 116-140. https://doi.org/10.1016/j.rser.2006.05.014

Gursel, A. P., Masanet, E., Horvath, A., \& Stadel, A. (2014). Lifecycle inventory analysis of concrete production: A critical review. Cement and Concrete Composites, 51, 38-48. https://doi.org/10.1016/j.cemconcomp.2014.03.005

He, B., \& Wang, G. (2019). Is ceramsite the last straw for sewage sludge disposal: A review of sewage sludge disposal by producing ceramsite in China. Water Science \& Technology, 80(1), 1-10. https://doi.org/10.2166/wst.2019.223

Krüger, O., \& Adam, C. (2015). Recovery potential of German sewage sludge ash. Waste Management, 45, 400-406. https://doi.org/10.1016/j.wasman.2015.01.025

Li, J. S., Xue, Q., Fang, L., \& Poon, C. S. (2016). Characteristics and metal leachability of incinerated sewage sludge ash and air pollution control residues from Hong Kong evaluated by different methods. Waste Management, 64, 161-170. https://doi.org/10.1016/j.wasman.2017.03.033

Lin, D.-F., \& Weng, C.-H. (2001). Use of sewage sludge ash as brick material. Journal of Environmental Engineering, 127(10), 922-927. https://doi.org/10.1061/(ASCE)0733-9372(2001)127:10(922)

Lombardi, L., Nocita, C., Bettazzi, E., Fibbi, D., \& Carnevale, E. (2017). Environmental comparison of alternative treatments for sewage sludge: An Italian case study. Waste Management, 69, 365-376. https://doi.org/10.1016/j.wasman.2017.08.040

Lynn, C. J., Dhir R. K., Ghataora G. S., \& West R. P. (2015). Sewage sludge ash characteristics and potential for use in concrete. Construction and Building Materials, 98, 767-779. https://doi.org/10.1016/j.conbuildmat.2015.08.122

Lynn, C. J., Dhir, R. K., \& Ghataora, G. S. (2018). Environmental impacts of sewage sludge ash in construction: Leaching assessment. Resources, Conservation and Recycling, 136, 306314. https://doi.org/10.1016/j.resconrec.2018.04.029

Lundin, M., Olofsson, M., Pettersson, G. J., \& Zetterlund, H. (2004). Environmental and economic assessment of sewage sludge handling options. Resources, Conservation and Recycling, 41(4), 255-278.

https://doi.org/10.1016/j.resconrec.2003.10.006 
Mohajerani, A., Ukwatta, A., \& Setunge, S. (2018). Fired-clay bricks incorporating biosolids: Comparative life-cycle assessment. Journal of Materials in Civil Engineering, 30(7), 1-12. https://doi.org/10.1061/(ASCE)MT.1943-5533.0002308

Nakić, D. (2018). Environmental evaluation of concrete with sewage sludge ash based on LCA. Sustainable Production and Consumption, 16, 193-201. https://doi.org/10.1016/j.spc.2018.08.003

Nakić, D., Vouk, D., Donatello, S., \& Anić-Vučinić, A. (2017). Environmental impact of sewage sludge ash assessed through leaching. Engineering Review, 37(2), 222-234. https://hrcak.srce.hr/181515

Nakić, D., Vouk, D., Serdar, M., \& Cheeseman, C. R. (2020). Use of MID-MIX treated sewage sludge in cement mortars and concrete. European Journal of Environmental and Civil Engineering, 24(10), 1483-1498. https://doi.org/10.1080/19648189.2018.1474383

Oliva, M., Vargas, F., \& Lopez, M. (2019). Designing the incineration process for improving the cementitious performance of sewage sludge ash in Portland and blended cement systems. Journal of Cleaner Production, 223, 1029-1041. https://doi.org/10.1016/j.jclepro.2019.03.147

Ottosen, L. M., Bertelsen, I. M. G., Jensen, P. E., \& Kirkelund, G. M. (2020). Sewage sludge ash as resource for phosphorus and material for clay brick manufacturing. Construction and Building Materials, 249, 118684. https://doi.org/10.1016/j.conbuildmat.2020.118684

Shi, H. S., \& Kan, L. L. (2009). Leaching behavior of heavy metals from municipal solid wastes incineration (MSWI) fly ash used in concrete. Journal of Hazardous Materials, 164(2-3), 750-754. https://doi.org/10.1016/j.jhazmat.2008.08.077

Shih, P., Chang, J., Lu, H., \& Chiang, L. (2005). Reuse of heavy metals containing sludges in cement production. Cement and Concrete Research, 35(11), 2110-2115.

https://doi.org/10.1016/j.cemconres.2005.08.006
Suh, Y. J., \& Rousseaux, P. (2002). An LCA of alternative wastewater sludge treatment scenarios. Resources, Conservation \& Recycling, 35(3), 191-200. https://doi.org/10.1016/S0921-3449(01)00120-3

Świerczek, L., Cieślik, B. M., \& Konieczka, P. (2018). The potential of raw sludge in construction industry - A review. Journal of Cleaner Production, 200, 342-356. https://doi.org/10.1016/j.jclepro.2018.07.188

Vouk, D., Nakić, D., Štirmer, N., \& Cheeseman, C. R. (2018). Influence of combustion temperature on the performance of sewage sludge ash as a supplementary cementitious material. Journal of Material Cycles and Waste Management, 20, 14581467. https://doi.org/10.1007/s10163-018-0707-8

Vouk, D., Serdar, M., Nakić, D., \& Anić-Vučinić, A. (2016). Use of sludgegenerated at WWTP in the production of cement mortar and concrete. Civil Engineer, 68(3), 199-210. https://doi.org/10.14256/JCE.1374.2015

Wittmaier, M., Langer, S., \& Sawilla, B. (2009). Possibilities and limitations of life cycle assessment (LCA) in the development of waste utilization systems - Applied examples for a region in Northern Germany. Waste Management, 29(5), 1732-1738. https://doi.org/10.1016/j.wasman.2008.11.004

Zhou, Y., Li, J., Lu, J., Cheeseman, C. R., \& Poon, C. S. (2020b). Recycling incinerated sewage sludge ash (ISSA) as a cementitious binder by lime activation. Journal of Cleaner Production, 244, 118856. https://doi.org/10.1016/j.jclepro.2019.118856

Zhou, Y., Li, J., Lu, J., Cheeseman, C. R., \& Poon, C. S. (2020a). Sewage sludge ash: A comparative evaluation with fly ash for potential use as lime-pozzolan binders. Construction and Building Materials, 242, 118160.

https://doi.org/10.1016/j.conbuildmat.2020.118160 